\title{
La primera crisis de SEAT: el veto a General Motors y la compra de AUTHI a British Leyland (1972-1976)
}

\author{
The first crisis of SEAT: the veto to General Motors and \\ the purchase of AUTHI to British Leyland (1972-1976)
}

\author{
JORDI CATALAN VIDAL \\ Universitat de Barcelona
}

RESUMEN

En 1972 SEAT era la primera empresa industrial hispana y lideraba la exportación de automóviles, gracias a una política favorable a la nacionalización productiva. Pero la política industrial del franquismo tardío dio un giro copernicano con la aprobación de los decretos Ford. Dicho vuelco incluyó, en 1973, la invitación a General Motors

a salvar la filial de British Leyland Motor Corporation (BLMC), AUTHI. Más que una imposición gubernamental, la compra de Landaben por SEAT en 1975 constituyó la contrapartida del veto a la entrada de General Motors. La resultante ampliación de plantilla era poco recomendable para una compañía que experimentaba un notable crecimiento de costes laborales desde 1969 y una peligrosa caída de la demanda desde 1974. Además, el cambio de política y el posterior incumplimiento del pacto contribuyeron a enturbiar las relaciones con FIAT, acabando con la "luna de miel" en que se desenvolvían sus relaciones desde 1970.

PALABRAS CLAVE: Industria del automóvil, SEAT, General Motors, BLMC, FIAT, Ford, España

Códigos JEL: L62, N64, N84, O14

\section{ABSTRACT}

In 1972 SEAT was the first Spanish industrial firm and led the export of automobiles, thanks to a nationalist policy. However, the industrial policy of late Francoism experienced a dramatic change with the approval of Ford's decrees. Such a change included the invitation to General Motors to rescue the Spanish subsidiary of British Leyland Motor Corporation (BLMC), AUTHI, in 1973. The purchase of its plant in Landaben by SEAT in 1975 has to be considered more the consequence of a pact preventing the entrance of General Motors than the outcome of direct pressure by government. The increase in the size of employment resulted to be a very risky decision for a company which was experiencing a significant push on labour costs since 1969 and a dangerous fall in demand since 1974. Moreover, the change of policy and the further removal of the veto on General Motors, would contribute to jeopardize the relationship with FIAT, ending the honey moon experienced during the early seventies.

KEY WORDS: Automobile industry, SEAT, General Motors, BLMC, FIAT, Ford, Spain

JEL Codes: L62, N64, N84, O14 


\section{Introducción ${ }^{1}$}

$\mathrm{E}$

ntre la Guerra de Corea y el estallido del primer shock petrolero, España pasó de una posición irrelevante como fabricante de automóviles (la decimoctava) al décimo lugar del ranking internacional ${ }^{2}$. El protagonismo del ascenso correspondió a SEAT, que en 1972 producía 2,6 veces más vehículos que FASARenault, el segundo fabricante del momento. Pese a sus orígenes autárquicos, la historia de SEAT durante la edad de oro de posguerra constituyó un éxito de la adopción de políticas estratégicas para desarrollar una industria clave, caracterizada por operar en un marco de competencia oligopolística con importantes rendimientos de escala. La política nacionalista también contribuyó a cambiar la ventaja comparativa de la economía española, al frenar las importaciones, estimular las exportaciones y permitir el aprendizaje industrial. Hasta 1972 dicha política fue compatible con rentabilidades positivas de SEAT. Entonces, la casa de la Zona Franca de Barcelona no sólo era la primera empresa fabril peninsular en ventas y valor añadido; figuraba, además, como la segunda más rentable entre las grandes sociedades participadas por el INI. Aunque no se había librado de la erosión de beneficios (profit-squeezing) de finales de la edad dorada europea, su rentabilidad se mantenía ligeramente por encima de la media de la gran empresa no financiera española. A nivel internacional, si bien SEAT quedaba malparada respecto a los constructores alemanes, su rentabilidad resultaba similar a la de FIAT o la Régie Renault ${ }^{3}$.

Es bastante conocido que en 1972, con la aprobación de los decretos Ford, se abrió una nueva etapa en la historia económica de la automoción ${ }^{4}$. Menos sabido es que, junto al acercamiento de la administración española a Ford, hubo también un

[Fecha de recepción del original, octubre de 2006. Versión definitiva, mayo de 2007]

1 He de agradecer a Elena Laruelo, Ana Sisnierga y al personal del Centro de Documentación de SEPI, el acceso a los fondos del INI correspondientes a Registro General (AINIRG), Altos Cargos (APresidencia) y Secretaría del Consejo (AConsejo). La documentación relativa a SEAT en estos archivos ha constituido el principal fondo de fuentes utilizadas. Guiaron mis primeros pasos en el centro, Antonio Gómez Mendoza, Elena Laruelo, Elena San Román, Ana Sisnierga y Miguel Ángel Martínez Sevilla. He contado, además, con el apoyo financiero del MEC (proyectos BC 2002-0043 y SEJ 2005-02498) y las fundaciones Eduardo Barreiros y Duques de Soria. Me han servido de estímulo las críticas de los asistentes a los seminarios organizados por Jordi Nadal, José Luis García Ruiz y Carles Sudrià. La penúltima versión de este papel fue discutida por Elena San Román en el Seminario de Historia Económica de la Universidad Complutense de Madrid, organizado por Juan Hernández Andreu y José Antonio Sebastián Amarilla. Varios de los colegas presentes aportaron valiosas sugerencias. A todos y a los tres evaluadores anónimos de Investigaciones de Historia Económica hago extensivo mi agradecimiento.

2 Sólo Japón experimentó una mejora relativa comparable a la española, al subir del décimo al segundo puesto. Catalan (2000), pp. 115 y 150.

Catalan (2006), pp. 177, 178 y 180.

Sudrià y San Román (2000), pp. 82-83; García Ruiz (2001), pp. 147-152, y (2003), p. 13. 
intento desde el Ministerio de Industria de atraer a General Motors. Este artículo pretende estudiar cómo dicha apertura del franquismo tardío hacia el capital norteamericano afectó al proceso de desarrollo de SEAT.

A partir de 1974, la crisis de la sociedad mostró su virulencia. El segundo objetivo del trabajo es explicar por qué, en un momento de intensa recesión y exceso de capacidad, SEAT adquirió la planta de Landaben a British Leyland Motor Corporation (BLMC, en adelante). Entre los estudiosos de la historia de la empresa tiene un fuerte arraigo la idea de que dicha compra fue una imposición gubernamental ${ }^{5}$. A la luz de la documentación estudiada, veremos como dicha hipótesis requiere revisión.

Desde 1969, SEAT había comenzado a protagonizar el despegue en las exportaciones españolas de automóviles y a desempeñar un papel destacado en alterar la ventaja comparativa de la economía española. Contra lo que a veces se cree, y tal como sugiere el Gráfico 1, el momento decisivo en que España pasó a ser exportadora neta de autos fue la primera mitad de los años setenta. La tercera intención de este artículo es mejorar nuestro conocimiento de los condicionantes de las ventas exteriores del principal exportador de vehículos en la mencionada coyuntura.

Por último, el artículo pretende examinar en qué medida la apertura hacia América del franquismo tardío dañó los lazos entre SEAT y FIAT. Antes de 1972, las relaciones entre ambas eran prometedoras. FIAT poseía alrededor del 36 por 100 del capital de SEAT y contaba con un buen aliado estratégico en el Banco Urquijo (con un 8 por 100 del mismo). En 1970, Giovanni Agnelli había acabado aceptando tres reivindicaciones históricas del INI: impulso a la exportación, reducción del canon tecnológico y creación de un centro tecnológico. Contrariamente, en 1980, y después de una breve cohabitación durante la cual los hombres de FIAT asumieron la dirección de SEAT, Corso Marconi decidió renunciar a la toma de la mayoría absoluta de la filial y abandonarla ${ }^{6}$. Para entender por qué Turín y Madrid pasaron de la cooperación al conflicto conviene conocer los compromisos de la primera fase de la crisis de SEAT.

Solé nos dice que "... el Gobierno presidido por Carlos Arias Navarro impuso a SEAT en 1975 la adquisición de la fábrica que la British Leyland-Authi poseía en Pamplona". Solé (1994), p. 30. Llorente apunta que SEAT adquirió Pamplona “... por indicación del Gobierno...". Llorente (1997), p. 276. Di por buena la versión en Catalan (2000), p. 142. Gimeno seguía en la misma dirección: "La patata caliente de Authi preocupaba mucho en estos momentos de crisis política por el problema social que podría representar, por lo que el gobierno dio instrucciones al INI para que SEAT se hiciese cargo de la fábrica de Landaben". Gimeno (2002), p. 44. Roca continua afirmando que "Con todo, este año 1975 es el del principio del fin de la hegemonía de SEAT ya que el gobierno le va obligar a asumir la compra de la fracasada Authi...". Roca (2006), p. 113. En el otro extremo, tenemos a González de la Fe, quien no presta atención ni hace referencia alguna a la motivación detrás de la compra de Landaben. Sin embargo, sí considera entre los puntos fuertes de SEAT el contar, hacia 1982, con instalaciones "modernas y eficientes" en Pamplona. Gónzalez de la Fe (2003), p. 104.

$6 \quad$ Catalan (2003), pp. 34-36. 


\section{GRÁFICO 1}

VENTAJA COMPARATIVA REVELADA EN LA EXPORTACIÓN DE AUTOMÓVILES DESDE ESPAÑA, 1961-2002 $(\operatorname{Ln}($ Xaut/Maut $) /($ Xtotal/Mtotal $))$

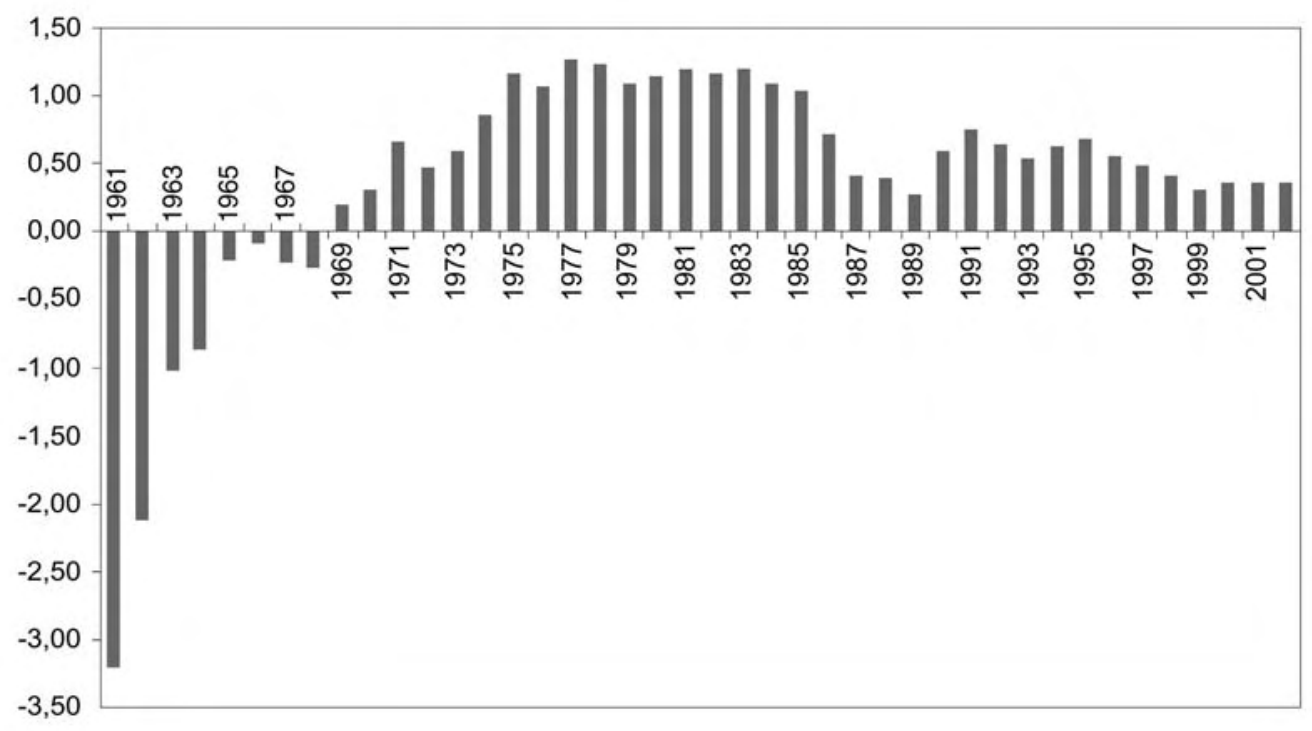

Fuentes: Elaboración propia a partir de la Estadística de Comercio Exterior de España.

\section{El regreso de Ford}

En diciembre de 1971, el ministro de Industria, José María López de Letona, hizo públicos sus contactos con Ford y manifestó su disponibilidad a llegar a un acuerdo con la firma de Detroit ${ }^{7}$. A mediados de 1972, el director general de Industrias Siderometalúrgicas y consejero de SEAT, Carlos Pérez de Bricio Olariaga ${ }^{8}$, expuso al consejero delegado de la misma, Rafael Cabello de Alba y Gracia ${ }^{9}$, los contenidos de un proyecto de decreto que pretendía abrir la posibilidad de implantar en España plantas de montaje de automóviles ${ }^{10}$. Dicho proyecto no sólo confirmaba la amenaza del

$7 \quad$ Pérez Sanchó (2003), p. 131. Para conocer la estrategia de desembarco de Ford en el mercado europeo del pequeño turismo durante los años setenta, es fundamental Tolliday (2003), pp. 201-227. La primera experiencia de Ford en España se describe en Estapé (2003), pp. 439-450.

8 Según Pérez Sanchó, que cita a Dorz, López de Letona y Pérez de Bricio fueron quienes llevaron la negociación con Ford. Pérez Sanchó (2003), p. 164.

9 Cabello de Alba había sido nombrado vicepresidente y consejero delegado de SEAT en diciembre de 1971.

10 "Carta de Rafael Cabello de Alba a Claudio Boada. Madrid, 5/07/1972", AINIRG 5012, 3544, p. 1. 
regreso de la multinacional americana, sino que apuntaba la posibilidad de rebajar notablemente el grado de nacionalización, la exigencia, hasta entonces vigente, de incorporación de un mínimo del 90 por 100 de materiales y componentes locales en la fabricación de vehículos.

A comienzos de julio de 1972, SEAT ya había elaborado un documento en que manifestaba su opinión sobre la posible instalación de nuevas plantas en régimen de montaje $\mathrm{e}^{11}$. La compañía mostró su oposición a la propuesta gubernamental de rebajar el grado de nacionalización hasta el 40 por 100. Los perjuicios serían más intensos si la autorización de grados de nacionalización bajos se concedía a fabricantes no establecidos en España. La alternativa de SEAT era aprovechar el desarme arancelario y la ampliación de contingentes que permitía el Acuerdo Preferencial entre España y la CEE de 1970. Abogaba por autorizar mayores importaciones de turismos, solución menos irreversible y más fácilmente graduable.

En el mismo mes, Cabello comunicó dicha posición al presidente del INI, Claudio Boada Villalonga. Pronosticó que la infrautilización provocada por las nuevas plantas afectaría especialmente a los fabricantes con mayor capacidad instalada ${ }^{12}$.

Gracias a las actas del Sindicato de Accionistas de SEAT, conocemos cómo se planteaban las relaciones entre Turín y Madrid en la vigilia de la aprobación de los decretos Ford. A la reunión del 28 de septiembre de 1972 en Madrid asistieron, entre otros, pesos pesados: Umberto Agnelli (consejero delegado de FIAT), Juan Sánchez-Cortés y Dávila (presidente de SEAT), Juan Lladó y Sánchez-Blanco (consejero delegado del Banco Urquijo), Boada y Cabello. Los presentes acordaron diferenciar dos etapas en la evolución de las relaciones entre SEAT y FIAT. La primera (1972-1976) vendría determinada por la continuidad del marco de mercado protegido, pero en un contexto de intensificación de la competencia. El sindicato identificaba el riesgo de menores ventas interiores y la oportunidad de integración en un grupo multinacional ${ }^{13}$. También acordaba seguir con la renovación de la gama de vehículos para el mercado interior, pero con las menores inversiones posibles. Para después de 1977 preveía una mayor vinculación con el Mercado Común. En dicha perspectiva, planteaba la hipótesis de integración con un grupo multinacional -las negociaciones para una posible fusión FIATCitroën aún estaban calientes, y el 2 de octubre SEAT y Citroën-Hispania firmarían el acuerdo para crear INDUGASA, dedicada a fabricar juntas homocinéticas en VigoAdemás, dejaba patente la voluntad de especializar a SEAT en la fabricación de algunos modelos y partes. La estrategia era coherente con el programa que recientemente

11 “Consideraciones sobre la posible instalación en España de plantas automovilísticas en régimen de montaje. Madrid, 3/07/1972", AINIRG 5012, 3544.

“Carta de Rafael Cabello de Alba a Claudio Boada. Madrid, 5/07/1972", AINIRG 5012, 3544, p. 2.

13 "Nota Verbal de la Reunión del Sindicato de Accionistas de SEAT en 28/09/72", APresidencia 64, V-165, 17. 
había fijado el Comité de Dirección de Turín: sustituir la política tradicional de plantas completas para vehículos por la de especializar las plantas exteriores en producción de partes, armonizar la red comercial a nivel de grupo e intensificar el esfuerzo en $\mathrm{I}+\mathrm{D}^{14}$.

El 23 de octubre de 1972, Cabello envió a López de Letona una misiva acompañada de un documento que exponía la posición de SEAT y FASA-Renault ante la inminente autorización de la rentrée de Ford ${ }^{15}$. Citroën-Hispania, aunque invitada a sumarse al acuerdo por SEAT, declinó firmar el documento, puesto que pretendía aprovechar la nueva regulación para montar el GS en Vigo ${ }^{16}$. Barcelona y Valladolid expresaban sus temores sobre cinco grandes problemas previsibles: los competidores se establecerían en España con inversiones inferiores, la dependencia aumentaría, las nuevas marcas crearían redes permanentes, la reducción de cuotas de mercado dificultaría los planes con las propias licenciadoras y el precedente empujaría a nuevos grupos internacionales. Las predicciones no distaron mucho de la realidad.

Entre las alternativas, proponían aumentar la gama de vehículos disponibles para el consumidor y fomentar la exportación a base de autorizar a los fabricantes establecidos menores porcentajes de nacionalización. Dicha política podía encajar con la directriz FIAT de elevados grados de nacionalización para productos de masas y bajos para el resto. Se correspondía, asimismo, con la estrategia de producto impulsada por SEAT durante 1972: lanzaba el 127, nuevo utilitario de tracción delantera (1.010 c.c.), concebido para grandes series y producido íntegramente en la Zona Franca; preparaba la fabricación de una nueva berlina de gama alta, el 132, con motores de 1.600-1.800 c.c., construidos en Barcelona y carrocerías estampadas en Italia; y estudiaba, además, la producción del sustituto del 600, el futuro 133, que iba a combinar la carrocería del 127 con el motor del $850^{17}$.

Sin embargo, Dearborn se llevó el gato al agua. El 10 de noviembre, Henry Ford II, presidente de la firma de Michigan, se entrevistó al mediodía con López de Letona y, por la tarde, con el presidente del Gobierno, almirante Luis Carrero Blanco. Al día siguiente, fue recibido por el Príncipe de Asturias ${ }^{18}$. El día 30 del mismo mes, el gobierno aprobaba el Decreto 3339/1972, que rebajaba del 90 al 50 por 100 el mínimo obligatorio de componentes nacionales para los nuevos constructores. Proponía, además, incrementar las series de fabricación de modelos básicos nacionalizados, ampliar la capacidad de las plantas existentes e impulsar el montaje con firmas extranjeras.

\footnotetext{
Castronovo (1999), p. 1.263.

“Carta de Rafael Cabello de Alba a José María López de Letona, 23/10/1972”, AINIRG 5012, 3554.

"Carta de Rafael Cabello de Alba a Claudio Boada. Madrid, 5/07/1972", AINIRG 5012, 3544.

Acta del Consejo de Administración de SEAT [a partir de ahora, Acta] 260, 24/05/1972. Las actas figuran en las cajas correspondientes a SEAT del AINIRG.

18 Parece que, precisamente, don Juan Carlos pensaba en López de Letona para sustituir a Arias al frente del gobierno en el crítico mes de noviembre de 1975. Tusell y Queipo de Llano (2003), p. 233.
} 
El 23 de diciembre, el Decreto 3757/1972 declaraba al automóvil como sector preferente $^{19}$. Las empresas podrían obtener desgravaciones fiscales, facilidades en terrenos, crédito oficial y reducciones arancelarias. Los requisitos exigibles fueron una producción de 500 vehículos diarios, series de 400 para un modelo básico o 200 para dos, inversión en activos fijos superior a los 7.000 millones de pesetas, exportación mínima del 20 por 100 y nuevos puestos de trabajo.

Ford formalizó su solicitud el 30 de diciembre, declarando una inversión de 310 millones de dólares para una fábrica de 240.000 vehículos. El Gobierno la aprobó, fijándole un límite de ventas en España del 10 por 100 de la matriculación. Parece que dicho límite era el previsto en los planes de la transnacional americana, cuyo proyecto iba orientado hacia el mercado europeo, aprovechando la rebaja arancelaria del Acuerdo Preferencial. Ayudado por los servicios del gabinete Garrigues, Ford obtuvo generosos subsidios ${ }^{20}$. Dearborn siguió la táctica de hacer competir a las provincias de Valencia y Zaragoza ${ }^{21}$. Pérez de Bricio señalaría que las concesiones aragonesas sirvieron a Detroit para exprimir a voluntad al Instituto de Promoción Industrial de Valencia ${ }^{22}$. Zaragoza perdió la partida, pero quiso resarcirse por la vía de seguir ofreciendo ventajosas condiciones a otros constructores de automóviles: SEAT, primero, y General Motors, después.

\section{El proyecto de Zaragoza}

Desde 1970, la compañía de la Zona Franca tenía intención firme de construir una segunda planta. En marzo, su Consejo de Administración había aprobado el proyecto de erigir en los nuevos terrenos de Martorell una fábrica con capacidad anual para más de 250.000 vehículos. Pero el ministro de Industria, López de Letona, y el presidente del INI, Boada, lo frenaron. El primero, el 8 de octubre, durante un almuerzo con representantes de SEAT y del Urquijo, apuntó la posibilidad de fusión con sociedades "mal estructuradas como Citroën, AUTHI o Chrysler"23. Boada añadió que cualquier desarrollo del plan de Martorell debía quedar subordinado a una solución previa de los problemas de Citroën y de AUTHI.

\footnotetext{
19 “Planes Generales de Expansión de SEAT a Medio y Largo Plazo 1972-1980. Noviembre 1973", AINIRG $5159,3554$.

$20 \quad$ Pérez Sanchó (2003), pp. 133-143.

21 Germán, citando a Mené, apunta que dicha dinámica de competencia entre Valencia y Zaragoza, llevaría a las "fuerzas vivas zaragozanas" a "solicitar al poco tiempo, la instalación de una nueva fábrica SEAT...". Germán (2003), p. 186.

22 Ver la cita de Pérez Sanchó (2003), p. 63.

23 Catalan (2006), p. 174.
} 
En 1971, SEAT había empezado a proyectar su ambicionado Centro Técnico, perfilando el programa de $\mathrm{I}+\mathrm{D}^{24}$. La división de prototipos comenzaría estudiando modificaciones en carrocerías y adaptaría el 127. Las pruebas de suministros pasarían a efectuarse en el nuevo centro. Los materiales se someterían a tests de fatiga. Se abordaría el estudio de gases de escape, seguridad y defectos de los vehículos. También se incorporarían secciones de perfeccionamiento de motores, transmisiones y cajas de cambio, y desarrollo de modelos deportivos. A principios de 1972, la compañía había realizado un estudio para evaluar el coste del emplazamiento del Centro Técnico en tres localizaciones del curso bajo del Llobregat: Zona Franca, Martorell y Sant Andreu de la Barca ${ }^{25}$. El trabajo concluyó que la Zona Franca pecaba de sobresaturación, caros arrendamientos en terrenos adyacentes y falta de la exención de aranceles de que disfrutaba SEAT en el emplazamiento originario. Martorell gozaba de la ventaja del terreno en propiedad, pero requería infraestructuras y tampoco contaba con franquicia arancelaria. Sant Andreu exigía, además, un desembolso adicional para adquirir los terrenos. Al final la liza siguió abierta con sólo dos candidatos, Barcelona y Martorell.

En el transcurso de 1973 los terrenos de Martorell fueron ampliándose ${ }^{26}$. Se construyeron los accesos e iniciaron las obras de los tres primeros edificios. Además del Centro Técnico, la capital del Baix Llobregat iba a albergar el Almacén Central de Recambios, con suministro de componentes para modelos cuya fabricación cesaba (el 1500 en 1972 y el 600 en 1973). También se adquirieron terrenos en Azuqueca de Henares (Guadalajara) para construir un segundo Almacén de Recambios y abastecer a Castilla, Andalucía y Galicia ${ }^{27}$.

Mientras Ford negociaba el lugar de su definitivo emplazamiento, SEAT adaptaba sus planes a la nueva política de Industria. El 23 de mayo un informe insistió en las limitaciones de la Zona Franca ${ }^{28}$. La falta de espacio para materiales era presentada como un grave obstáculo para los nuevos modelos. La plantilla de 24.000 trabajadores en Barcelona se consideraba excesiva ${ }^{29}$. Además, el documento de mayo de 1973 proponía el traslado de elaboraciones mecánicas a Martorell (donde se emplearían 2.700 personas) y la creación de una nueva planta de fabricación y mon-

\footnotetext{
24 “Programa de Investigación y Desarrollo 28/10/71", AConsejo, DG Ingeniería Electrónica 12, B-3-12.

25 "Estudio Económico sobre el Emplazamiento del Centro Técnico en Diversas Zonas, 19/04/71", AConsejo, DG Ingeniería Electrónica, 12, B-3-12.

26 SEAT, Memoria y Balance que el Consejo de Administración somete a la Junta general ordinaria de Accionistas correspondiente al Ejercicio 1973 en el día 19 de abril de 1974, Madrid, p. 17.

27 SEAT, Memoria y Balance que el Consejo de Administración somete a la Junta general ordinaria de Accionistas correspondiente al Ejercicio 1973 en el día 19 de abril de 1974, Madrid, p. 23.

"Informe sobre nuevos desarrollos de SEAT. 23/05/73", AINIRG 5159, 3554.

29 La dirección de SEAT debía tener en mente la intensificación de la conflictividad laboral que conllevó la muerte de Ruiz Villalba en 1971. Lucchetti (2003), p. 291.
} 
taje de vehículos en un tercer emplazamiento (con 9.000 nuevos trabajadores). Para las series con grado de nacionalización superior al 90 por 100, Zona Franca mantendría los modelos de pequeña y mediana cilindrada (133 y 127), con capacidades respectivas de 500 y 800 unidades por día. En menor nacionalización, Barcelona produciría un nuevo modelo de 1.300-1.600 c.c. (sustituto del 124/1430) y seguiría con el modelo 132 (1.600-1.800 c.c.), recién lanzado. Los outputs diarios alcanzarían las 300 y 100 unidades. La capacidad adicional de Zona Franca exigiría una inversión de 2.690 millones de pesetas, que debería añadirse a los planes de expansión ya en marcha (9.151 millones). Martorell acogería las secciones de suspensiones y otros elementos mecánicos, que serían montados en Barcelona. Su capacidad de trabajo alcanzaría hasta 1.700 vehículos diarios. Para conseguirlo requeriría una inversión de 2.191 millones de pesetas. La tercera fábrica produciría 500 unidades de un nuevo modelo de cilindrada media (1.100-1.300 c.c.), con un grado de nacionalización del 90 por 100 . Además, alojaría instalaciones de montaje de hasta tres modelos distintos, con bajo recurso a componentes nacionales y capacidad de 150 unidades diarias. El coste de la nueva planta se evaluaba en 14.208 millones de pesetas.

El plan subrayaba la necesidad de un fuerte incremento de la colaboración FIATSEAT en los ámbitos de inversiones, producción, redes comerciales de exportación, $\mathrm{I}+\mathrm{D}$, compras y formación. Los intercambios se potenciarían con ventas diarias de Barcelona a Turín de 200 motores del modelo 127 y 250 unidades de motores bialberos de alta cilindrada. En contrapartida, FIAT vendería a SEAT piezas y conjuntos para fabricar los 550 vehículos diarios de menor nacionalización. La localización de la nueva fábrica debería decidirse en función de la ayuda de las administraciones locales ${ }^{30}$.

La estrategia de SEAT vino influida por el curso de las negociaciones de Ford con los agentes locales. El 15 de junio de 1973 el pleno de la Diputación de Valencia aprobaba la ayuda para la construcción de Almussafes. Los aragoneses se movieron y ofrecieron terrenos y financiación a SEAT. Su Consejo de Administración, reunido el 19 de junio, decidió aprobar la nueva fábrica en Zaragoza con capacidad diaria de 500 vehículos y montaje de otros $150^{31}$. Para Cabello, la opción pretendía dar respuesta a tres retos: la nueva ordenación jurídica, la insuficiencia de la Zona Franca y el compromiso con FIAT ${ }^{32}$. El plan financiero asumía contar con un crédito oficial de

\footnotetext{
30 "Informe sobre nuevos desarrollos de SEAT. 23/05/73", AINIRG 5159, 3554, p. 4.

31 Cabello ofreció las claves de por qué la capital aragonesa fue escogida: “... ha parecido conveniente la localidad de Zaragoza, que se propone por la posibilidad de encontrar terrenos en magnífica situación y óptimas condiciones, aparte de la extraordinaria acogida que han tenido los propósitos de esta Sociedad por las autoridades provinciales y locales, y asimismo las fuerzas económicas de aquella región...". Acta 271, 19/06/1973, p. 9.

$32 \quad$ Acta 271, p. 6.
} 
9.544 millones de pesetas, aportaciones de las cajas de ahorros de 7.000 millones y crédito a la exportación de 2.356 millones, lo que representaba un monto de 18.900 millones de financiación de procedencia pública o privilegiada. Además, se preveía una autofinanciación de 20.547 millones. La perspectiva era favorable, aunque había que descontar 5.673 millones de créditos anteriores ${ }^{33}$. Para optar a las ayudas del decreto de sector preferente, también se adelantaba una exportación de entre el 20 y el 30 por 100.

En noviembre se concluyó el programa, que llegaba hasta 1980. Apuntaba que la exportación no debía rebasar el 30 por 100, puesto que el mercado internacional no permitía rentabilidad suficiente por soportar derechos arancelarios en la CEE y mayores costes de componentes interiores. Una diferencia significativa con anteriores proyectos residía en que quedaban explícitas las tres condiciones básicas: asignación de crédito oficial por el 70 por 100 del valor de las inversiones previstas en inmovilizado fijo, concesión de los máximos beneficios fiscales otorgables según el decreto 3757 y disponibilidad urgente de los terrenos zaragozanos. SEAT consiguió para el proyecto los beneficios ligados a la declaración de sector de interés preferente. También se acogió a los beneficios de desgravación establecidos por el Decreto Ley 19/1971, quedando exenta de pagar el impuesto de sociedades en 1973.

\section{Industria invita a General Motors}

Para hacer frente a la tremenda crisis por la que pasaba el fabricante AUTHI, el gobierno español llamó a la puerta de General Motors (GM, en adelante) en abril de $1973^{34}$. La empresa navarra venía arrastrando grandes pérdidas desde sus orígenes y en el transcurso de 1973 la situación parecía insostenible ${ }^{35}$. La administración había pedido antes a Ford que se responsabilizara del excedente de plantilla de AUTHI, pero aquélla declinó la oferta ${ }^{36}$. Los hombres del tardofranquismo buscaron un nuevo amigo americano.

\footnotetext{
$33 \quad$ Acta 271, p. 11.

34 Así se desprende de la carta de BLMC a Arias Navarro de 7 de diciembre de 1974, que ha servido para confeccionar esta sección. APresidencia 217, 4. Aznar y Aparicio (2000), p. 26, apuntan una tentativa de implantación de GM en España “...que coincidió con la instalación de Ford en Valencia; se abrió entonces un largo período de negociaciones que concluyeron en 1975, nuevamente sin acuerdo". Ambos autores, aunque no dan referencias, sugieren la existencia de un vínculo entre la llegada de Ford y el intento de General Motors. Se les escapa que es el gobierno español y no los americanos quienes dan el primer paso.

35 Ver el testimonio del abogado y procurador en Cortes, Ezponda, citado por De la Torre (2001), nota 37, p. 22.

$36 \quad$ Pérez Sanchó (2003), p. 141.
} 
El 16 de abril de 1973, siendo todavía ministro López de Letona, el director general de Industrias Siderometalúrgicas se entrevistó en Nueva York con directivos de $\mathrm{GM}^{37}$. Pérez de Bricio sugirió a la compañía estadounidense que considerase adquirir las acciones de la filial española. A raíz de la propuesta se iniciaron los contactos entre la primera empresa automovilística mundial y el accionista mayoritario de AUTHI, BLMC ${ }^{38}$. Durante el mes de mayo BLMC aumentó su participación en AUTHI hasta el 98 por 100 del capital ${ }^{39}$.

El 19 de septiembre de 1973 GM devolvió la visita a Pérez de Bricio en Madrid y discutió la propuesta de compra de las acciones británicas ${ }^{40}$. El 2 de noviembre la primera empresa automovilística mundial hizo llegar por escrito a López de Letona la propuesta consensuada en las conversaciones anteriores. El 21 del mismo mes, GM y BLMC firmaban una carta de intenciones por la que la primera le compraba sus acciones en AUTHI. El 15 de diciembre los directivos americanos se entrevistaban con el ministro, quien parece que daba el visto bueno a la propuesta de $\mathrm{GM}^{41}$. Pero cinco días más tarde el presidente del Gobierno, el almirante Carrero, fallecía en un atentado. El nuevo presidente, Carlos Arias Navarro, escogió para la cartera de Industria a Alfredo Santos Blanco. Pérez de Bricio sobrevivió en su Dirección General. Recibió el anteproyecto de GM el 8 de febrero de 1974. Al frente del INI, el Gobierno había situado a Francisco Fernández Ordóñez, quien estaría en el cargo sólo entre febrero y octubre. Eligió para director de planificación económica e industrial al ingeniero donostiarra Juan Miguel Antoñanzas Pérez-Egea, quien acumulaba experiencia en la absorción de una compañía automovilística española (Barreiros) por otra gran hermana americana (Chrysler $)^{42}$.

Fernández Ordóñez asistió como presidente del INI a la reunión del Sindicato de Accionistas de SEAT de 13 de marzo de 1974, en la que se discutió la compra de AUTHI por $\mathrm{GM}^{43}$. El consejero delegado de SEAT, Cabello, tomó la palabra y señaló que la autorización de la inversión de GM impediría alcanzar los objetivos de la legislación de 1972. Añadió que ésta significó el abandono de la política anterior de concentraciones empresariales, impulsada por López Bravo y el propio López de

37 John Barber, presidente de BLMC, al inicio de su carta a Arias Navarro pondría de manifiesto que “... no fue British Leyland Motor Corporation quien, a este respecto se puso en contacto con General Motors, sino precisamente a la inversa y ello por que la empresa americana había tenido ocasión de recibir al Sr. Pérez de Bricio...". APresidencia 217, 4, p. 1.

"Anexo a la carta de John Barber al Presidente del Gobierno, 7/12/1974", APresidencia 217, 4, p. 1. Gimeno y Roca (1997), p. 45.

"Anexo a la carta de John Barber al Presidente del Gobierno, 7/12/1974", APresidencia 217, 4, p. 1.

“Anexo a la carta de John Barber al Presidente del Gobierno, 7/12/1974", APresidencia 217, 4, p. 1. Martín Aceña y Comín (1991), p. 138; García Ruiz y Santos Redondo (2001), p. 223; y Gimeno (2002), p. 49. “Nota verbal de la reunión del Sindicato de Accionistas de SEAT, 13/03/1974. Adjunta a carta de Juan Sánchez-Cortés a Juan Miguel Antoñanzas de 16/10/1975", APresidencia 217, 30. 
Letona. Insistió en que la autorización conllevaría exceso de capacidad y problemas para la exportación ${ }^{44}$. El sector se dirigiría desde fuera. Aumentarían las presiones de otros fabricantes. Por último, el valor supuestamente pagado por AUTHI, 3.600 millones de pesetas, se consideraba una prima muy notable a BLMC ${ }^{45}$.

A renglón seguido Cabello sugirió cinco opciones. La primera consistía en denegar la autorización a GM. La quinta era estudiar una asociación entre SEAT y el gigante automovilístico estadounidense. La cuarta propuesta de Cabello debe examinarse con particular detalle, pues se convertiría en la única que aparece doblemente subrayada al margen en la copia del acta que conservó el INI y que figura junto a una carta que Sánchez-Cortés remitió a Antoñanzas (para entonces responsable del Instituto) el 16 de octubre de 1975:

\begin{abstract}
" 4 a . Posibilidad de que AUTHI fuese comprada por SEAT. [Cabello] Precisa que en tal caso sería necesario el adquirirla por su estricto valor de saldo y solicitar al Gobierno la garantía de que GM no se intenta instalar en España por otra vía, bien mediante la compra de otra sociedad fabricante, o bien a través del Decreto..."46.
\end{abstract}

El fragmento goza de gran interés porque quien hizo la propuesta se habría convertido en el vicepresidente segundo del gobierno cuando SEAT compró Landaben. Permite mantener tres nuevas interpretaciones: primera, SEAT adquirió Pamplona por voluntad propia; segunda, la obtuvo a precio de saldo; y tercera, la compró a cambio de que en ningún caso se autorizaría la entrada en España de GM.

Cabello concluyó su exposición inicial aclarando lo siguiente:

“... la solución ideal sería la primera, pero... en todo caso parece conveniente el tener prevista la posibilidad de ofrecer la adquisición de AUTHI por SEAT en las condiciones expresadas en el punto $4^{\circ \prime \prime}$.

A continuación, el acta de la reunión del Sindicato de Accionistas de SEAT señala que los asistentes alabaron la exposición de Cabello. Entre ellos figuraban el presidente de SEAT (Sánchez-Cortés), el ariete del Urquijo (Lladó) y varios representantes de FIAT. La reunión concluyó con tres grandes conclusiones unánimes. Las

“Nota verbal de la reunión del Sindicato de Accionistas de SEAT, 13/03/1974. Adjunta a carta de Juan Sánchez-Cortés a Juan Miguel Antoñanzas de 16/10/1975", APresidencia 217, 30, p. 2.

45 La empresa navarra había reducido por pérdidas su capital desde 1.400 millones a sólo 140 y luego lo había ampliado hasta 2.400 durante el ejercicio anterior. Además, en 1969, cuando SEAT había negociado la compra de AUTHI, el valor solicitado era de 3.024 millones, y desde entonces el resultado poco brillante de la compañía no justificaba el sobreprecio.

46 "Nota verbal de la reunión del Sindicato de Accionistas de SEAT, 13/03/1974. Adjunta a carta de Juan Sánchez-Cortés a Juan Miguel Antoñanzas de 16/10/1975", APresidencia 217, 30, p. 7. 
dos primeras insistían en el quebranto para SEAT que representaría la instalación en España de GM y la necesidad de ofrecer una alternativa constructiva al gobierno. Dicho second best se dibujaba en la tercera conclusión, que proponía la adquisición de AUTHI por SEAT con cuatro condiciones: un precio realista para las instalaciones; obtención de ayuda financiera pública; la certeza de que General Motors vería prohibida su entrada en España "definitivamente"; y la posibilidad de reconsiderar el destino último de las instalaciones adquiridas ${ }^{47}$.

Por otra parte, el anteproyecto de GM fue formalmente entregado al gobierno de Arias tres meses después, el 17 de junio de 1974. Además, los representantes de AUTHI y BLMC se reunieron con el subsecretario de Industria, Landelino Lavilla, el 24 de junio ${ }^{48}$. Éste se entrevistó en Nueva York con los hombres de GM y sugirió algunos cambios. La nueva propuesta estadounidense fue comunicada en agosto de 1974.

El 14 de septiembre Santos Blanco recibió al presidente de AUTHI, quien subrayó la dramática posición de la empresa navarra y la urgencia de tomar una decisión. Santos prometió respuesta para finales de mes. Algunas semanas más tarde era el propio vicepresidente del Gobierno y ministro de Hacienda, Antonio Barrera de Irimo, quien se reunía en Washington con ejecutivos de GM. Las conversaciones con Industria siguieron el 22 de octubre en Madrid y el día 25 GM incorporaba nuevas exigencias del Ministerio ${ }^{49}$.

Sin embargo, el 29 de octubre de 1974 Arias reajustó su gobierno y Barrera fue sustituido en sus cargos por el hasta entonces consejero delegado de SEAT, Cabello de Alba. Es difícil evitar pensar que éste renunciase a poner en marcha la estrategia presentada a su Sindicato de Accionistas en la primavera anterior ${ }^{50}$.

Por otra parte, desde finales de 1973, la coyuntura mundial había ido virando marcadamente a raíz de los efectos de la guerra de Yom Kippur, entre los que sobresale la cuatriplicación de los precios del petróleo. Para SEAT, el año 1973 fue todavía tiempo de vacas gordas, pero el siguiente ejercicio resultó el peor desde su constitución como sociedad. Las exportaciones, que habían alcanzado un máximo durante 1973 (con 78.789 vehículos), retrocedieron un 27 por 100 en volumen durante 1974. El Cuadro 1 recoge la interrupción de la tendencia creciente que el valor de las exportaciones de SEAT mostraba desde finales de los años sesenta. Entre 1969 y 1973, el valor exportado por SEAT se había multiplicado por más de diez, hasta acercarse a

47 “Nota verbal de la reunión del Sindicato de Accionistas de SEAT, 13/03/1974. Adjunta a carta de Juan Sánchez-Cortés a Juan Miguel Antoñanzas de 16/10/1975", APresidencia 217, 30, pp. 9-10.

48 "Anexo a la carta de John Barber al Presidente del Gobierno, 7/12/1974", APresidencia 217, 4, p. 2.

49 "Anexo a la carta de John Barber al Presidente del Gobierno, 7/12/1974", APresidencia 217, 4, p. 2.

50 Mi interpretación contrasta con la de Gimeno y Roca que, si bien subrayan el buen entendimiento alcanzado por GM y BLMC en 1974 y el entusiasmo de Industria, atribuyen el fracaso de la operación a la oposición de Ford. Gimeno y Roca (1997), p. 47. 


\section{CUADRO 1}

RESULTADOS Y MARGEN DE SEAT POR TIPO DE ACTIVIDAD, 1969-1975

(millones de pesetas)

\begin{tabular}{|c|c|c|c|c|c|c|c|}
\hline & 1969 & 1970 & 1971 & 1972 & 1973 & 1974 & 1975 \\
\hline \multicolumn{8}{|l|}{ Costes } \\
\hline Autos interior & 20.380 & 21.713 & 23.583 & 29.069 & 37.557 & 38.787 & 44.846 \\
\hline Exportaciones & 534 & 1.912 & 2.755 & 2.862 & 4.515 & 4.380 & 5.121 \\
\hline Recambios y partes & 922 & 1.233 & 1.321 & 1.750 & 2.734 & 2.898 & 3.792 \\
\hline Talleres y servicios & 208 & 270 & 336 & 411 & 490 & 651 & 632 \\
\hline Financieros y otros & 334 & 392 & 752 & 915 & 686 & 945 & 1.356 \\
\hline Total & 22.378 & 25.520 & 28.746 & 35.006 & 45.982 & 47.662 & 55.745 \\
\hline \multicolumn{8}{|l|}{ Ingresos } \\
\hline Autos interior & 21.034 & 21.925 & 24.596 & 30.132 & 38.447 & 39.926 & 45.354 \\
\hline Exportaciones & 428 & 1.952 & 2.628 & 3.064 & 4.892 & 4.257 & 5.351 \\
\hline Recambios y partes & 1.077 & 1.482 & 1.589 & 2.006 & 3.101 & 3.111 & 4.044 \\
\hline Talleres y servicios & 204 & 251 & 281 & 318 & 352 & 423 & 326 \\
\hline Financieros y otros & 426 & 759 & 417 & 575 & 522 & 317 & 733 \\
\hline Total & 23.168 & 26.369 & 29.512 & 36.096 & 47.313 & 48.034 & 55.808 \\
\hline \multicolumn{8}{|l|}{ Resultados } \\
\hline Autos interior & 654 & 212 & 1.014 & 1.064 & 889 & 1.139 & 509 \\
\hline Exportaciones & -107 & 40 & -126 & 203 & 377 & -123 & 230 \\
\hline Recambios y partes & 154 & 250 & 268 & 255 & 367 & 214 & 252 \\
\hline Talleres y servicios & -4 & -19 & -54 & -92 & -138 & -229 & -305 \\
\hline Saldo financiero y otros & 92 & 367 & -335 & -340 & -164 & -628 & -623 \\
\hline Beneficio del ejercicio & 790 & 849 & 766 & 1.090 & 1.331 & 373 & 62 \\
\hline \multicolumn{8}{|c|}{ Margen por actividad (en \%) } \\
\hline Autos interior & 3,1 & 1,0 & 4,1 & 3,5 & 2,3 & 2,9 & 1,1 \\
\hline Exportaciones & $-24,9$ & 2,0 & $-4,8$ & 6,6 & 7,7 & $-2,9$ & 4,3 \\
\hline Recambios y partes & 14,3 & 16,9 & 16,9 & 12,7 & 11,8 & 6,9 & 6,2 \\
\hline Talleres y servicios & $-2,0$ & $-7,6$ & $-19,3$ & $-29,0$ & $-39,4$ & $-54,1$ & $-93,6$ \\
\hline Saldo financiero y otros & 21,6 & 48,4 & $-80,4$ & $-59,0$ & $-31,4$ & $-197,9$ & $-85,0$ \\
\hline Margen del ejercicio & 3,4 & 3,2 & 2,6 & 3,0 & 2,8 & 0,8 & 0,1 \\
\hline
\end{tabular}

Fuentes: Informe económico-financiero al balance de SEAT, varios años, AINIRG, Cajas 4852, 5159, 5331,5505 y 5689. 
los 5.000 millones de pesetas. Aunque el inicio de las grandes exportaciones de vehículos de la Zona Franca se había hecho con pérdidas (especialmente en 1969), la compañía automovilística había logrado equilibrar sus resultados en el exterior a principios de los setenta. Durante 1972 y 1973 los márgenes en las exportaciones habían incluso sido superiores a los obtenidos con las ventas domésticas. En cambio, durante 1974 las exportaciones volvieron a cerrarse con números rojos.

La caída del mercado doméstico de SEAT no fue tan perceptible debido a que el gobierno español prefirió seguir alimentando artificialmente la coyuntura. El número de vehículos fabricados por SEAT todavía aumentó ligeramente durante 1974 (hasta alcanzar un máximo de 364.695 unidades). Sin embargo, las ventas interiores, que durante 1973 habían aumentado más del 25 por 100 (gracias al éxito del 127 y a la novedad del 132), se estancaron. El lanzamiento del 133 no constituyó un revulsivo suficiente para compensar el cese de fabricación del $600^{51}$.

Las existencias de productos terminados pasaron de 2.862 millones de pesetas a 5.001 millones durante 1974. Ello contribuyó a hinchar los costes financieros de la empresa, partida que, junto a talleres y asistencia, cerraba con números rojos desde 1971. No obstante, y a diferencia de lo que sucedía con los talleres, en 1972 y 1973, se había logrado invertir la tendencia al crecimiento neto del coste financiero. En cambio, el saldo negativo de la cuenta financiera de SEAT volvió a aumentar durante 1974. El beneficio declarado se redujo en un 72 por 100, su mayor declive histórico. El margen sobre ventas se encogió, pasando del 2,8 a sólo el 0,8 por 100. La cotización media de las acciones en la Bolsa de Madrid se desplomó desde el 440 al 268 por 100 del valor de la par (Gráfico 2).

La dirección reconoció, tímidamente, el cambio de escenario, aprobando la reducción del dividendo del 12 al 8 por 100. Asimismo, intentó negociar un expediente de regulación de empleo de 39 días para 1975, lo que representaría una reducción del 15 por 100 de los días laborales. El clima reivindicativo de la coyuntura dificultaba la comprensión de la crisis al movimiento obrero. En un informe sindical de noviembre de 1974 para negociar la regulación, se argumentaba que la situación financiera era "mejor en todos sus aspectos a la de 1972 y 1973"52. La caída de las exportaciones se atribuía a presiones de FIAT y al descuido del mercado exterior ${ }^{53}$. Los asesores de los representantes obreros aceptaban retrasar la expansión futura de la empresa (Martorell, Zaragoza, Guadalajara), pero no recortar producción. Pese a

51 El sustituto del 600 nunca alcanzó unas ventas anuales de 50.000 unidades, como era la norma habitual de su predecesor.

52 Lucchetti, A., Fina, L., y otros: "Informe Técnico presentado por los trabajadores de SEAT, SA", copia mecanografiada, Barcelona, 29/11/1974, p. 44.

53 Lucchetti, A., Fina, L., y otros: "Informe Técnico presentado por los trabajadores de SEAT, SA", copia mecanografiada, Barcelona, 29/11/1974, p. 51. 


\section{GRÁFICO 2}

COTIZACIÓN MEDIA DE SEAT EN LA BOLSA DE MADRID $(p a r=100)$

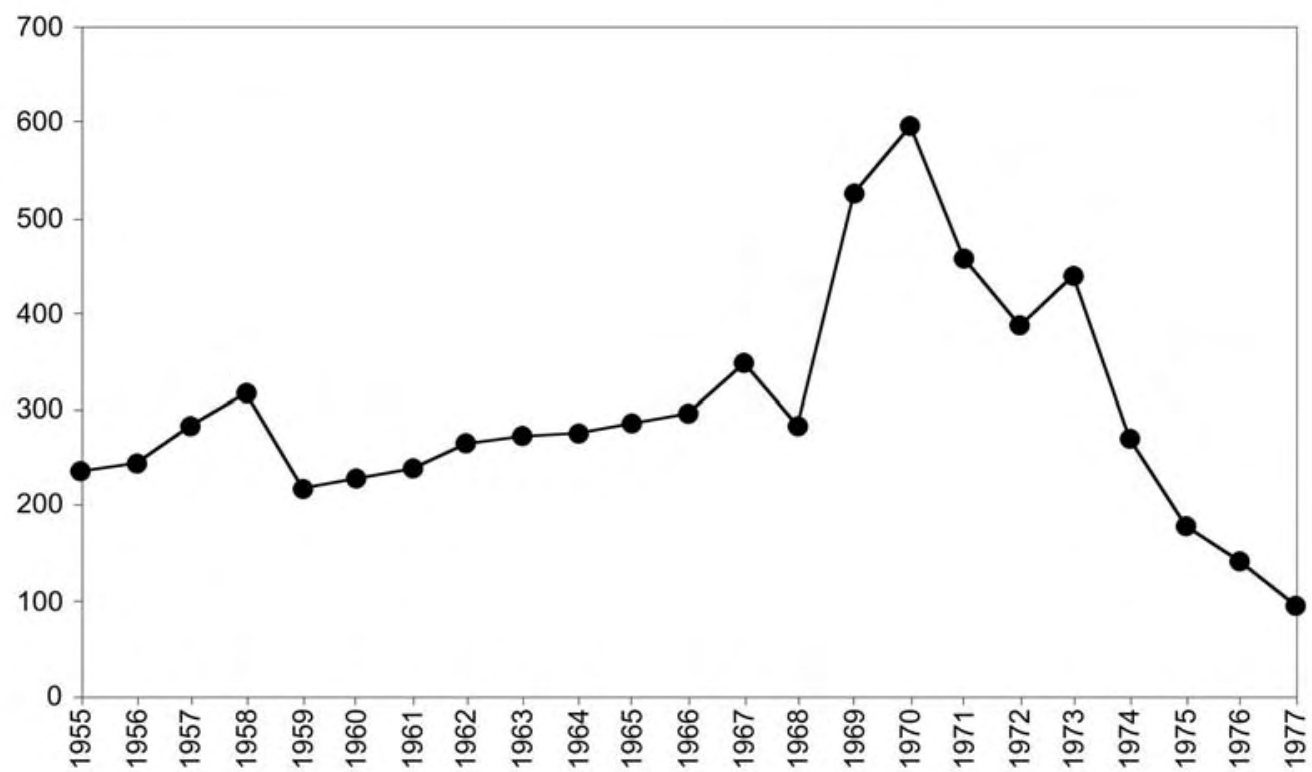

Fuentes: Banco de Bilbao, Agencia Financiera (varios años).

la oposición sindical, la compañía logró el visto bueno de la Delegación de Trabajo de Barcelona para aplicar un desempleo parcial de 31 días entre enero y abril de $1975^{54}$. Los trabajadores seguirían percibiendo su salario habitual, pero sin pluses de puntualidad, asistencia, nocturnidad habitual y trabajo peligroso. Sin embargo, la huelga hizo caer por sí misma la producción al inicio de 1975, retardando el recurso por la empresa a la regulación.

\section{Las tentaciones del INI}

Del lapso de presidencia de Fernández Ordóñez se guarda copia del acta de una reunión celebrada en Turín, el 10 de mayo de 1974, para estudiar el futuro de SEAT. 
Umberto Agnelli manifestó que la entrada de Ford o GM modificaba radicalmente la política industrial del gobierno español y dejaba obsoletos los acuerdos de 1967 y 1970 con el INI y SEAT ${ }^{55}$. El menor de los Agnelli añadió que el cambio implicaba un replanteamiento global de las relaciones SEAT-FIAT. Propuso como solución más conveniente para Turín, tomar la mayoría en el capital de SEAT. Una segunda posibilidad residía en asumir la gestión sin adquisición previa de la mayoría ${ }^{56}$. Ésta implicaría la creación de un órgano central controlado por FIAT, que decidiera sobre investigación, exportaciones y producción de SEAT.

El 27 de junio se entrevistaron en Turín Fernández Ordóñez, Antoñanzas y Umberto Agnelli. En dicha reunión, el presidente del INI comenzó recriminando a SEAT por estar exportando por debajo del 20 por 100 del output y posponer Zarago$\mathrm{za}^{57}$. Ofreció cinco alternativas a FIAT: mayor coordinación, incluyendo exportaciones de SEAT no inferiores al 20 por 100, inversiones en Zaragoza, investigación compartida y suministros industriales SEAT-FIAT; compra de la mayoría por el INI; compra de la mayoría por FIAT; venta de la participación del Instituto a un tercero; y venta de las acciones italianas a un tercero. Fernández Ordóñez acabó remarcando que Ford y GM estaban decididas a invertir en España ${ }^{58}$.

Agnelli recalcó sus dudas sobre la política iniciada en 1972 e insistió en que las previsiones pecaban de optimismo. Calificó la posición de Ford y GM en Europa de "seudocolonialismo"59. Respondió que la propuesta de coordinación podía considerarse como solución ideal. Sobre la nueva planta apuntó que "la decisión de ir a Zaragoza con las producciones previstas fue emocional y probablemente no justificada por las necesidades del mercado"60. Sugirió que si el problema de Zaragoza era laboral debería explorarse la posibilidad de fabricar allí otros productos FIAT o ubicar la producción de componentes por parte de grupos extranjeros. Añadió que Corso Marconi también estaba dispuesto a comprar las acciones del Instituto en SEAT, pero ello implicaba renunciar a Zaragoza ${ }^{61}$. Se mostraba asimismo abierto a vender sus acciones al INI, pero no deseaba ninguna solución de venta a terceros.

Según la transcripción: “En cierto sentido FIAT considera que otras empresas que han hecho menos esfuerzo por la industrialización de España han resultado más favorecidas. FIAT entiende que los derechos reconocidos a SEAT en los acuerdos de 1967 y 1970 respondían a una situación de hecho que se ha alterado profundamente con la opción política adoptada por el Gobierno español al abrir la fabricación de automóviles (y en cierta medida el mercado interior) a los grupos multinacionales". "Postura de FIAT en orden a las relaciones futuras FIAT-SEAT", APresidencia 217, 11, p. 2.

"Postura de FIAT en orden a las relaciones futuras FIAT-SEAT", APresidencia 217, 11, p. 4.

“Conversaciones con FIAT en Torino el 27/06/74", APresidencia 217, 9, p. 1.

“Conversaciones con FIAT en Torino el 27/06/74", APresidencia 217, 9, p. 6.

“Conversaciones con FIAT en Torino el 27/06/74", APresidencia 217, 10, p. 3.

"Conversaciones con FIAT en Torino el 27/06/74", APresidencia 217, 10, p. 3.

"Conversaciones con FIAT en Torino el 27/06/74", APresidencia 217, 10, p. 4. 
El 14 de julio se reunieron en Madrid los representantes del INI, FIAT, Banco Urquijo y SEAT, asistiendo Antoñanzas y Cabello. Los piamonteses insistieron en que los temas de inversiones y exportaciones constituían dos puntos críticos en las relaciones mutuas ${ }^{62}$. Sobre el primer punto, Turín remarcaba que tenía suficiente capacidad para cubrir la demanda española del 128. Sobre el segundo, proponía especializar a SEAT en las ventas exteriores del 133 y del 1274 puertas, productos específicos no fabricados por FIAT. En las conclusiones los italianos insistían en que el futuro de SEAT pasaba por la integración en el grupo multinacional a constituir con Turín. Una copia de esta acta fue enviada desde el INI a Pérez de Bricio el 19 de julio 63 .

Antoñanzas voló a Milán durante el mes de noviembre y negoció en Turín. El resumen de las conversaciones, durante las que también se planteó la posible colaboración ENASA-FIAT, está archivado con una carta de Antoñanzas al director general de la sede central de SEAT, Nicolás Andino Ruiz ${ }^{64}$. En dicho documento figura que la solución de SEAT residía en la toma de control de FIAT ${ }^{65}$. Los italianos expusieron que la situación de dos compañías con idénticos productos no era sostenible ni en Europa, ni en un mercado español liberalizado. Antoñanzas subrayó que el objeto de los encuentros era la integración de SEAT en FIAT ${ }^{66}$. Los locales señalaron que el Urquijo aceptaba realizar primero los planes industriales integrativos y, después de cinco años, la transmisión de acciones. De hecho, FIAT pasaba por una situación financiera muy delicada. En Italia se amontonaban existencias a resultas del shock petrolífero y los costes laborales se habían disparado desde la ofensiva sindical del Autunno Caldo ${ }^{67}$. Además, Turín se había embarcado en la construcción de una nueva fábrica en Bello Horizonte.

FIAT, por otro lado, ofrecía especializar las exportaciones y la I+D de SEAT en derivados: las versiones cuatro puertas y furgoneta del 127 y la furgoneta 238. Además, cedía la licencia de fabricación del 128 para montaje y un uso del 50 por 100 de

62 “Reunión en la sede social de SEAT, 14/07/1974", APresidencia 217, 14, p. 3.

63 Así consta en anotación manuscrita sobre la primera página del documento 14. "Reunión en la sede social de SEAT, día 14/07/1974", APresidencia 217, 14.

64 Andino sustituiría oficialmente a Cabello como consejero delegado en febrero de 1976. A diferencia de éste, no desempeñaría la función de vicepresidente, que seguiría recayendo en Francisco Urquijo. Acta 302, 26/02/1976, p. 3.

“Entendemos que la solución más razonable es la de integración SEAT en FIAT, aún cuando la oferta de opción de compra a cinco años, sugerida por FIAT a cambio de la mayoría no es satisfactoria...". "Información preparada por INI, 19/11/1974, Propuesta resumen", AINIRG 5332, Anexo a 1974.

Refiriéndose al objetivo del encuentro, Antoñanzas apuntó que era "desarrollar las posibilidades de futuro de una integración FIAT-SEAT y a este respecto expresó la necesidad de concretar el contenido de los ofrecimientos de FIAT a cambio del control de la mayoría". "Resumen de los temas tratados en la reunión de Turín del día 14/11/1974", AINIRG 5332, Anexo, p. 3. 
componentes españoles. SEAT dudó sobre la división del trabajo e insistió en complementar las exportaciones de derivados con las convencionales ${ }^{68}$. De hecho, el 127 $4 \mathrm{P}$ acabaría siendo un éxito de SEAT en el exterior (especialmente entre los taxistas italianos). Constituyó uno de los primeros resultados de la ingeniería de proyectos de SEAT bajo responsabilidad de Günter Oistrach, quien asistió a la mencionada reunión en el Piamonte, acompañando a Andino. En aquellos años, Oistrach también estuvo vinculado a la iniciativa de Antoni Amat, quien, en Terrassa, acabó construyendo un modelo deportivo basado en la plataforma del $127 \mathrm{y}$ apodado "bocanegra"69.

La dirección de Antoñanzas consideraba que la alternativa de mantenimiento de una SEAT autónoma, ambicionada por la propia compañía, conllevaba demasiado riesgo:

“...el INI y en definitiva el Estado español debería hacer un gran esfuerzo como estímulo a la industrialización del País... [y la solución exigiría] una necesidad muy extensa de protección"70.

La compra de la mayoría por FIAT parecía, a los ojos del INI, la solución más razonable. El problema principal de esa opción era que los Agnelli deseaban demorar la compra cinco años a fin de asegurarse que España ingresaba en la CEE.

En la sesión del Consejo de Administración del INI de 29 de noviembre de 1974, Antoñanzas informó de las negociaciones con FIAT. Como refleja el acta, el donostiarra remachó la tesis de la inviabilidad de la existencia de dos empresas fabricando indefinidamente los mismos productos ${ }^{71}$.

Por tanto, la evidencia documental indica que, a finales de 1974, la suerte parecía echada para la venta de SEAT a FIAT. Puede interpretarse dicha entrega como contrapartida a Turín por la entrada de GM en España ${ }^{72}$. La principal variable retrasando la operación parecía ser la falta de urgencia de Turín que, para asegurarse de la entrada en la CEE y por falta de liquidez, prefería dilatar la operación cinco años. En dicho contexto, el acceso del consejero delegado de SEAT a la vicepresidencia gubernamental conllevó un nuevo vuelco.

\footnotetext{
68 “Resumen de los temas tratados en la reunión de Turín del día 14/11/1974”, AINIRG 5332, Anexo, p. 4. 69 González (2004). El 1200 Sport, presentado en diciembre de 1975, tampoco tendría paralelo en Italia.

70 "Información preparada por INI, 19/11/1974, Propuesta resumen", AINIRG 5332, Anexo a 1974, p. 8-2.

71 "Consejo 29/11/74", AConsejo 373, 036, 2.

72 Además, en las negociaciones se barajó la toma de control de FIAT en ENASA.
} 


\section{La solución Cabello de Alba}

El acta del Consejo de Administración de SEAT de 21 de noviembre de 1974 recoge la felicitación unánime a Cabello por su elección como vicepresidente segundo del Gobierno. En el mismo día y acta se anunciaba la dimisión como consejero de SEAT de Pérez de Bricio $^{73}$.

Ya durante noviembre puede detectarse un cambio en la política de automóvil. Industria basculó hacia una solución doméstica para el problema navarro. El día 26, los máximos dirigentes de SEAT, FASA, Citroën y Chrysler se reunieron en Madrid a su requerimiento para buscar una solución a $\mathrm{AUTHI}^{74}$. Acordaron estar dispuestos a comprar las acciones de BMLC. Exigían, a cambio, crédito de la administración. También decidieron otorgar su representación para la gestión de la sociedad a la patronal del ramo, ANFAC. El episodio sugiere que comenzaba a desempolvarse la solución propuesta por Cabello al Sindicato de SEAT.

Tres días más tarde, el responsable del grupo británico en España, Paul Lewis, confirmaba a Andino que BLMC y GM ya habían firmado el contrato (¡de 1.000 folios!) de venta de las acciones de AUTHI y seguían a la espera de la autorización del gobierno español. El precio de la transacción se había establecido en 61 millones de dólares ${ }^{75}$.

En la presidencia del INI, Fernández Ordóñez era sustituido por Guerra Zunzunegui, quien ocupó el cargo menos de cuatro meses ${ }^{76}$. El 5 de diciembre de 1974 el Instituto obtenía de FIAT un borrador de acuerdo en el que Turín se comprometía a tomar entre el 51 y el 60 por 100 del capital de SEAT. La compra sería efectiva en el momento de entrada de España en la CEE o en el caso de que la política comercial española se armonizase con la comunitaria ${ }^{77}$. La propuesta borrador sobre la integración de SEAT en FIAT aparecía acompañada de unas notas sobre producción e inversiones futuras. Éstas presentaban la producción concentrada en dos centros: Zona Franca y "Nueva fábrica". Las inversiones en la primera priorizarían el desarrollo de la capacidad del 127. La última acogería el montaje del 128 y, posiblemente, del 238. La inversión total en cada uno de los casos ascendería a 28.078 millones o a 37.584 millones de pesetas, sin contar terrenos, accesos, laboratorios y ordenado-

Acta 287, 21/11/1974.

“Acuerdos de Juan Sánchez-Cortés, José Luis Rodriguez Pomatta, Estanislao Chaves y Jean Pierre Pisano. Madrid, 26/11/1974", AConsejo 373, 036.

75 "Nota reservada sobre la reunión celebrada en Madrid el día 29/11/1974 entre Mr. Paul Lewis, de la BLMC, y el Sr. Andino de SEAT", AINIRG 5332, Anexo.

76 Martín Aceña y Comín (1991), p. 338.

77 "Borrador 12.1974. INI-Banco Urquijo (en representación y con el ruego de informar a los Bancos Accionistas)", AINIRG 5332, Anexo a 1974, pp. 3-4. 
res. Ante la posibilidad de un "eventual aprovechamiento de la Fábrica de la Empresa Authi", el documento apuntaba unas economías medias de 2.000 millones $^{78}$.

El 11 de febrero de 1975 AUTHI suspendió pagos. El 11 de marzo una nueva crisis de gobierno se llevó por delante al ministro de Industria y al presidente del INI. Alfonso Álvarez Miranda y Antoñanzas se convirtieron en los nuevos responsables respectivos. Casi simultáneamente, la entonces críptica prensa española anunciaba la posible absorción de SEAT por FIAT. El 15 de marzo, el Diario de Navarra se hacía eco de un artículo de la publicación italiana Panorama, donde se preveía que FIAT aumentase su cuota en el capital de la empresa de Zona Franca del 33 al 51 por 100. El corresponsal en Roma del periódico vasco también se hacía eco del encuentro entre sindicalistas en el Instituto Gramsci de Turín, donde afloró la noticia de la toma de control por FIAT. Los representantes ibéricos fueron presentados como despedidos de SEAT de 1971. Días más tarde publicaciones españolas como Cambio 16, Nuevo Diario, Ya o Arri$b a$, tomaban posiciones ante las noticias ${ }^{79}$. Tanto Madrid como Turín las desmintieron.

Umberto Agnelli y el nuevo responsable del INI se reunieron de urgencia en Madrid en la vigilia de primavera. Gracias a una carta del primero a Antoñanzas de 21 de marzo de 1975, en la que el menor de los Agnelli agradecía el almuerzo en casa del vasco, sabemos que la fuga informativa de Turín vino acompañada de un cierto maquillaje del proyecto de integración: no variaría la participación en el capital, pero se iría a la integración de productos y a la formación de facto de un holding internacional ${ }^{80}$.

El 18 de marzo SEAT había preparado una oferta firme para BMLC. Las actividades de AUTHI eran entonces tres: construcción de vehículos en Landaben, fabricación de motores y equipo mecánico en Los Corrales de Buelna (Cantabria) y producción de asientos en Santpedor (alrededores de Manresa). El tándem FIAT-Urquijo se había opuesto firmemente a la adquisición de las instalaciones de AUTHI en $1969^{81}$.

78 “Notas sobre las nuevas fábricas modelo 128 y modelo 238". Documento adjunto a “Borrador 12.1974. INIBanco Urquijo (en representación y con el ruego de informar a los Bancos Accionistas)", AINIRG 5332, Anexo a 1974 .

79 Andino envió una carta al nuevo ministro de Industria, Álvarez Miranda, con los recortes de las publicaciones mencionadas, cuyas copias se encuentran archivadas por el INI. APresidencia 217, G 19.

80 En la traducción de la carta de Agnelli a Antoñanzas podemos leer lo siguiente:“Como final de nuestras conversaciones deseo confirmar que en el más breve plazo posible propondremos un plan de acción que [...] sin necesidad de variar las actuales participaciones accionarias o, francamente, si lo considera politicamente útil, dando al INI la posibilidad de aumentar su propia participación, permita a SEAT, asumiendo sus riesgos empresariales de una manera coordinada, el fabricar, en un determinado período de tiempo, productos completamente integrables, en términos económicos, para un mercado español abierto, con los productos FIAT [subrayados a mano en la copia de la traducción de la carta]. Prepararemos, por consiguiente, un programa como si [subrayado en la versión original de FIAT] SEAT y FIAT debieran al cabo de cinco años, formar parte de un mismo "holding internacional". Traducción de carta de 21/03/1975 de Umberto Agnelli a Antoñanzas, APresidencia 217, G 20.

81 Catalan (2006), pp. 170-175. 
Seis años más tarde, FIAT seguiría objetando la compra de la fábrica cántabra, pero acabaría aceptando la de Pamplona, porque implicaba vetar a GM y podía conllevar la absorción de SEAT.

SEAT ofrecía por Landaben 1.100 millones de pesetas, y 150 por Santpedor. Sólo se comprometía a ayudar a la compra de Los Corrales por terceros, debido a la frontal negativa de FIAT a la inversión en la localidad montañesa ${ }^{82}$.

En abril de 1975, Turín desveló su plan de acción, donde defendía la unificación de la red comercial con SEAT en vistas a la integración en la CEE ${ }^{83}$. FIAT añadía su intención de encargarse completamente de la dirección de SEAT, tal como se había ido pactando en las reuniones periódicas ${ }^{84}$. La sociedad piamontesa asumía la integración de facto de las dos compañías y el mantenimiento de una autonomía aparente de SEAT, tal como requería el INI. No obstante, exigía garantías de salvaguarda:

"FIAT ha comprendido los motivos sicológicos y políticos que sugieren realizar la unión operativa de hecho sin una inmediata unión financiera; por ello, formula la presente propuesta en las condiciones actuales de la estructura financiera de SEAT. Sin embargo, considera indispensable prever soluciones adecuadas de tipo financiero en la hipótesis de que la solución asociativa de hecho necesitara su empleo. Habiendo dejado a un lado, por los mencionados motivos, la idea de ejercer un derecho de opción, se considera necesario prever un derecho de recesión de la participación SEAT a un precio convenido y valorado desde ahora a precios constantes de 1974 en base a los criterios usuales de valoración" 185 .

El 6 de mayo de 1975, Andino envió un dossier a Antoñanzas en el que figuraba la propuesta de SEAT sobre AUTHI de marzo. Cuando se trata el tema de la compra de Los Corrales, aparece un añadido mecanografiado, destacado en entorno circular y subrayado con la leyenda: "Totalmente objetado por FIAT". "Carta de 18/03/1975 a AUTHISA, pendiente acuerdo del Consejo de SEAT", APresidencia, 65, Oferta de SEAT a AUTHI sobre Pamplona y Santpedor, 5, p. 4.

Según la propuesta italiana: “Las producciones españolas se integrarán en las producciones italianas, de forma que resulte posible la comercialización de las dos producciones en una sola red", "Traducción del escrito propuesto por FIAT, en el que se señalan en rojo los párrafos que se propone suprimir en el borrador. 30/04/1975. Evolución de las Relaciones entre FIAT y SEAT", APresidencia, Oferta de SEAT a AUTHI sobre Pamplona y Santpedor, 1, p. 2.

FIAT añadía lo siguiente: “Con el fin de asegurar una unidad de dirección empresarial para el grupo italoespañol, FIAT está dispuesta a asumir la responsabilidad total de la integración y, de forma particular, de los resultados de SEAT, a condición de que obtenga la efectiva autoridad en la planificación...". "Traducción del escrito propuesto por FIAT, en el que se señalan en rojo los párrafos que se propone suprimir en el borrador. 30/04/1975. Evolución de las Relaciones entre FIAT y SEAT", APresidencia, Oferta de SEAT a AUTHI sobre Pamplona y Santpedor, 1, p. 3.

85 “Traducción del escrito propuesto por FIAT, en el que se señalan en rojo los párrafos que se propone suprimir en el borrador. 30/04/1975. Evolución de las Relaciones entre FIAT y SEAT", APresidencia, Oferta de SEAT a AUTHI sobre Pamplona y Santpedor, 1, p. 3. 
En documento adjunto, FIAT se refería a la renuncia de GM a entrar en España y a la propuesta local de comprar AUTHI. Destacaba dos aspectos de las negociaciones: integración productiva y mantenimiento de la participación accionarial ${ }^{86}$. Para 1975, preparaba el lanzamiento del 131. FIAT también ofrecía a SEAT la exclusiva de la furgoneta 127 y el montaje del Lancia A/B. Para 1976, volvía a proponer el lanzamiento del 128. Preveía que el vehículo de mayor consumo doméstico (130.000 unidades) seguiría siendo el 127, seguido del 131 (50.000 unidades) y el 128 (42.000 unidades). Si bien FIAT aceptaba que, inicialmente, la dirección siguiese en manos españolas, el objetivo a medio plazo era la integración empresarial, implicando planificación conjunta de gama de productos, I+D, controles de calidad, aprovisionamientos y administración y finanzas. Turín priorizaba la coordinación de las exportaciones y la unificación de la red de ventas.

El 19 de mayo de 1975, SEAT envió su oferta a BMLC por Landaben y Santpedor $^{87}$. Condicionaba la compra a cuatro contrapartidas gubernamentales: crédito para financiarla, beneficios de la concentración de empresas con segregación de activos, extensión de las ventajas de industria preferente a Pamplona y autorización para disponer libremente de los bienes adquiridos. Además, figuraban condiciones menos taxativas, fiscales y administrativas, como obtener el apoyo de la Diputación de Navarra. En el capítulo de condiciones laborales, la compañía de la Zona Franca declaraba que no se subrogaría en ningún caso en las obligaciones contraídas por la filial de la firma británica ${ }^{88}$. Otra cláusula exigía un expediente de regulación de empleo hasta la puesta en marcha de los nuevos vehículos de SEAT.

\section{La compra de Landaben a BLMC}

El envío de la propuesta final se retrasó porque el Ministerio de Industria buscaba una alternativa para la fábrica de Los Corrales, que FIAT desechaba por completo. Industria negoció la segregación de la planta y su adquisición por Motor Ibérica (fundición), Bendibérica (compresores), Bosch (bombas) y Vam (embragues). El 26 de junio de 1975, Sánchez-Cortés confirmó a AUTHI las ofertas de 1.100 y 150 millones por

\footnotetext{
86 “Traducción del escrito propuesto por FIAT, en el que se señalan en rojo los párrafos que se propone suprimir en el borrador. 30/04/1975. Evolución de las Relaciones entre FIAT y SEAT", APresidencia, Oferta de SEAT a AUTHI sobre Pamplona y Santpedor, 1, p. 1.

87 "Carta de SEAT a AUTHISA, 19/05/1975", APresidentes, 65, H VI60, Oferta de SEAT a AUTHI sobre Pamplona y Santpedor, Anexo 6, pp. 2-4 y 6-7.

88 "Carta de SEAT a AUTHISA, 19/05/1975", APresidentes, 65, H VI60, Oferta de SEAT a AUTHI sobre Pamplona y Santpedor, Anexo 6, p. 3.
} 
Landaben y Santpedor, respectivamente ${ }^{89}$. Por la primera, SEAT desembolsaría 100 millones de pesetas a la firma del contrato y el resto del siguiente modo: hasta el 30 por 100 a la hora de la formalización de la escritura de transmisión; el 60 por 100 al obtener el crédito gubernamental, y el 10 por 100 al año de la consumación contractual. Finalmente, aceptó garantizar la continuidad del empleo en Pamplona y Manresa ${ }^{90}$.

El 27 de junio de 1975, el presidente de SEAT enviaba una copia de la oferta a su antiguo consejero delegado. La acompañaba una carta donde Sánchez-Cortés manifestaba a Cabello su intención de tramitar los expedientes de concentración de empresas ante el Gobierno y la Diputación Foral. Pedía, además, ampliar la financiación ofrecida por Madrid. Al final de la misma, señalaba que la compra de AUTHI era sólo una solución de recambio y no la óptima para superar la crisis de SEAT ${ }^{91}$.

En otra carta de Sánchez-Cortés remitida el mismo día al ministro de Trabajo, Fernando Suárez González, aquél exponía que la decisión podía ser, desde una óptica estrictamente empresarial, "dudosamente justificable"92. En una tercera misiva, esta vez al ministro de Relaciones Sindicales, Alejandro Fernández Sordo, añadía:

“De la lectura de ambos documentos se desprende la gravedad de los compromisos que adquirimos al contratar automáticamente y sin ninguna restricción al personal de las fábricas de AUTHI objeto de nuestra oferta, y muy especialmente al de la fábrica de Pamplona, que se ha caracterizado desde hace algún tiempo por su acusado grado de conflictividad"93.

El vértice de SEAT insinuaba una cierta desconfianza ante la compra. SánchezCortés manifestaba, incluso, dudas sobre su justificación empresarial. Aunque no pueda descartarse la hipótesis de que exagerara para obtener más contrapartidas, a mediados de 1975 el exceso de oferta derivado de la crisis era ya mucho más evidente que a principios de 1974. Durante marzo y abril de 1975, 17.000 trabajadores de la Zona Franca habían sido sometidos a regulación de empleo por falta de demanda. Según el balance oficial, al cerrar el ejercicio el margen sobre ventas bajaría del 0,8 al 0,1 por 100. A pesar de conflictos y regulaciones, los stocks de productos terminados de SEAT pasarían de 3.051 millones de pesetas a 6.778 millones. La deuda a corto plazo con proveedores aumentó desde 5.351 millones a 10.268 millones.

La fábrica de Santpedor sería revendida a Cometsa, que pasaría a suministrar asientos a SEAT.

Acta $295,16 / 07 / 1975$, p. 8.

Catalan (2006), p. 182.

Catalan (2006), nota 137.

"Carta de Juan Sánchez-Cortés a Alejandro Fernández Sordo", APresidencia 65, Oferta de SEAT a AUTHI sobre Pamplona y Santpedor, 5. 


\section{CUADRO 2}

ESTRUCTURA DE COSTES TOTALES DE SEAT, 1969-1976

(porcentajes)

\begin{tabular}{lrrrrrrrr}
\hline & $\mathbf{1 9 6 9}$ & $\mathbf{1 9 7 0}$ & $\mathbf{1 9 7 1}$ & $\mathbf{1 9 7 2}$ & $\mathbf{1 9 7 3}$ & $\mathbf{1 9 7 4}$ & $\mathbf{1 9 7 5}$ & $\mathbf{1 9 7 6}$ \\
\hline Materiales & 57,9 & 60,6 & 55,7 & 53,3 & 53,3 & 53,5 & 53,3 & 50,7 \\
Personal & 14,9 & 16,4 & 18,4 & 22,0 & 20,9 & 27,3 & 26,4 & 26,5 \\
Servicios externos & 11,4 & 9,1 & 11,3 & 8,4 & 10,6 & 5,3 & 10,8 & 10,4 \\
Financieros & 1,0 & 0,8 & 1,5 & 1,6 & 1,3 & 1,8 & 2,0 & 2,5 \\
Impuestos & 0,4 & 0,3 & 0,4 & 0,4 & 0,0 & 0,0 & 0,3 & 2,3 \\
Amortizaciones & 8,3 & 7,1 & 5,7 & 7,6 & 7,5 & 4,1 & 2,2 & 2,9 \\
Otros & 6,1 & 5,6 & 7,0 & 6,8 & 6,3 & 8,1 & 5,0 & 4,7 \\
\hline Total & $\mathbf{1 0 0 , 0}$ & $\mathbf{1 0 0 , 0}$ & $\mathbf{1 0 0 , 0}$ & $\mathbf{1 0 0 , 0}$ & $\mathbf{1 0 0 , 0}$ & $\mathbf{1 0 0 , 0}$ & $\mathbf{1 0 0 , 0}$ & $\mathbf{1 0 0 , 0}$ \\
\hline
\end{tabular}

Fuentes: Elaboración propia a partir del Estado comparativo de resultados (varios años), AINIRG, Cajas 4650, 4852, 5689 y 5872.

Si bien en 1975 las exportaciones y la cifra de negocio mejoraron, el Cuadro 1 indica que el beneficio se desvaneció. Además, por segundo año consecutivo los resultados encubrieron una fuerte reducción de amortizaciones, como apunta el Cuadro 2. La compañía dejaba de pagar dividendos y sus acciones seguían hundiéndose (Gráfico 2).

El Cuadro 2 sugiere, asimismo, la intensidad del problema laboral de la Zona Franca. Los costes del trabajo eran la partida con mayor crecimiento desde 1969. El peso del personal en la estructura de costes de SEAT había pasado del 14,9 al 27,3 por 100 en 1974. La ampliación de capacidad y plantilla en una coyuntura de significativa contracción de la demanda, no parece que pudiera ayudar a corregir el principal problema de la estructura de costes. En alguna medida, las cartas de SánchezCortés a Cabello, Fernando Suárez y Fernández Sordo, insinuaban dicha realidad.

SEAT, finalmente, había obtenido del gobierno español dos de las cuatro condiciones que se había fijado Cabello antes de sentarse en el Consejo de Ministros. Primera, el precio de 1.250 millones de pesetas por la parte apetecible de AUTHI (Pamplona y Santpedor) era mucho más favorable para SEAT que los 3.600 millones que, en teoría, estaba dispuesta a pagar GM por el conjunto (con la problemática fundición de Los Corrales). Segunda, la administración se mostraba dispuesta a financiar la parte del león de la inversión de SEAT: en 1975, Zona Franca negociaba un préstamo del Banco de Crédito Industrial por 1.100 millones para adquirir Landaben y otro de 3.000 millones para comprar maquinaria ${ }^{94}$. 
SEAT presupuestó para la compra de Pamplona, su acondicionamiento y equipo una suma de 3.506 millones $^{95}$. La adquisición y puesta en marcha de una planta adicional se lograba con un desembolso bastante más moderado que el planificado para Zaragoza. Pudiera haber sido un buen negocio en un momento de expansión de la demanda. Sin embargo, a mediados de 1975, momento de la compra, la coyuntura se manifestaba incuestionablemente recesiva. Un mes con la plantilla de SEAT parada podía exigir un desembolso en personal mínimo de unos 1.000 millones de pesetas. Por otra parte, SEAT no obtuvo carta blanca para reconvertir libremente Landaben, debiendo cargar con una plantilla abultada en un momento de claro exceso de capacidad, costes laborales desbocados y costes financieros en alza. Un aumento de personal en dicha coyuntura puede considerarse, como mínimo, una apuesta temeraria.

Finalmente, la condición de evitar la entrada en España de GM se consiguió a corto plazo, pero sólo por menos de un lustro. Dicho objetivo era la madre del cordero de toda la operación, tanto para SEAT como para FIAT. En un vuelco de lo que parecía la tendencia de la política industrial del franquismo tardío antes de la vicepresidencia de Cabello, la batalla parecía ganada con el veto gubernamental al intento de entrada de GM. No obstante, lo que se consiguió en 1975, no pudo evitarse durante la transición con los gobiernos de Adolfo Suárez. El atlantista titular de Industria, Agustín Rodríguez Sahagún, preparó en 1979 el decreto de instalación definitiva de GM en España (precisamente en Zaragoza) y su sucesor, Carlos Bustelo, lo ratificó. Ya bastante antes, la designación de Pérez de Bricio como ministro de Industria de los dos primeros gobiernos de la Monarquía presagiaba la vuelta a la línea pro-americana de López de Letona, después del último paréntesis de política industrial nacionalista.

SEAT acabó utilizando Landaben para fabricar el $124 \mathrm{D}$, un turismo ya bastante maduro. El primer vehículo navarro fue presentado en enero de 1976. Martorell se acondicionó para fabricar los puentes posteriores del 131. La Zona Franca montó el "bocanegra" y el 128. Éste quiso constituir una alternativa en la gama media-alta (1.200-1.430 c.c.). Sin embargo, en 1976, era otro producto algo obsoleto y nunca logró diferenciarse suficientemente de su antecesor.

Pese a la crisis internacional, SEAT logró un notable aumento de las exportaciones en 1976. Éstas remontaron de 62.687 a 76.988 vehículos, con protagonismo del 127 (68 por 100). SEAT, además, llegó a un acuerdo con la egipcia NASCO, para montar el 133 en Helwan ${ }^{96}$. Las ventas interiores (292.096 unidades) se acercaron a las previstas.

Acta 299, p. 10.

SEAT, Memoria y balance que el Consejo de Administración somete a la Junta general ordinaria de Accionistas correspondiente al Ejercicio 1976 en el día 28 de abril de 1977, Madrid, p. 25. 
Sin embargo, la transición intensificaría la presión salarial, desbordando los costes. En marzo de 1976, la Dirección General de Trabajo decretó una revisión salarial. Según la empresa, los costes salariales totales en 1976 registraron un aumento del 24 por $100^{97}$. Además, el régimen de precios autorizados impidió poder incrementar el precio de los automóviles no deportivos por encima del 8,5 por 100. De acuerdo con SEAT, la imposibilidad de repercutir el alza de costes sobre el precio de venta figuró entre las causas destacadas de las pérdidas del ejercicio. En el mes de junio, el consejero delegado, Andino, había recriminado ante el Consejo de Administración la política de precios de la Administración ${ }^{98}$. Según SEAT, el deterioro de la rentabilidad provocada por la no actualización de precios durante el primer shock del petróleo no tuvo parangón en otros países constructores de automóviles ${ }^{99}$. Desde 1973, los precios de los autos habían tendido a reflejar el aumento del coste de la vida en el resto de competidores. Por el contrario, tal como indica el Gráfico 3, en España los controles de precios habían provocado el abaratamiento real de los turismos durante el crítico intervalo de 1973-1976: al inicio de la transición, valían sólo un 88 por 100 del precio real promedio de 1973, mientras, por ejemplo, en Italia se vendían a un precio del 120 por 100 .

Además, Sánchez-Cortés confesaba ante el Consejo de Administración que SEAT se hallaba en una peligrosa situación de desventaja de costes por pagar unas retribuciones superiores en un 30 por 100 a la media del sector ${ }^{100}$. Las pérdidas ocasionadas por los talleres de asistencia y el cambio de tendencia en los costes financieros habían sido, asimismo, denunciadas durante 1976, tanto por Sánchez-Cortés como por Andino.

El ejercicio de 1976 acabó con el reconocimiento de los primeros resultados negativos de SEAT. Hasta entonces, los números rojos habían intentado disimularse con artimañas como recortar amortizaciones. Las pérdidas oficiales de 1976 ascendieron a 456 millones de pesetas. La compañía siguió sin pagar dividendos y la cotización de sus acciones cayó un ulterior 20 por 100. Las deudas afloraban. El reconocimiento oficial de la crisis se produjo en febrero de 1977, cuando dimitió el presidente Sánchez-Cortés. Para reemplazarlo, Pérez de Bricio, ascendido a ministro de Industria, escogió a Antoñanzas. correspondiente al Ejercicio 1976 en el día 28 de abril de 1977, Madrid, p. 21. 


\section{GRÁFICO 3}

ÍNDICES DE PRECIOS DE LOS AUTOMÓVILES Y PRIMER SHOCK DEL PETRÓLEO, 1976

(precios medios deflactados con el coste de la vida, $1973=100$ )

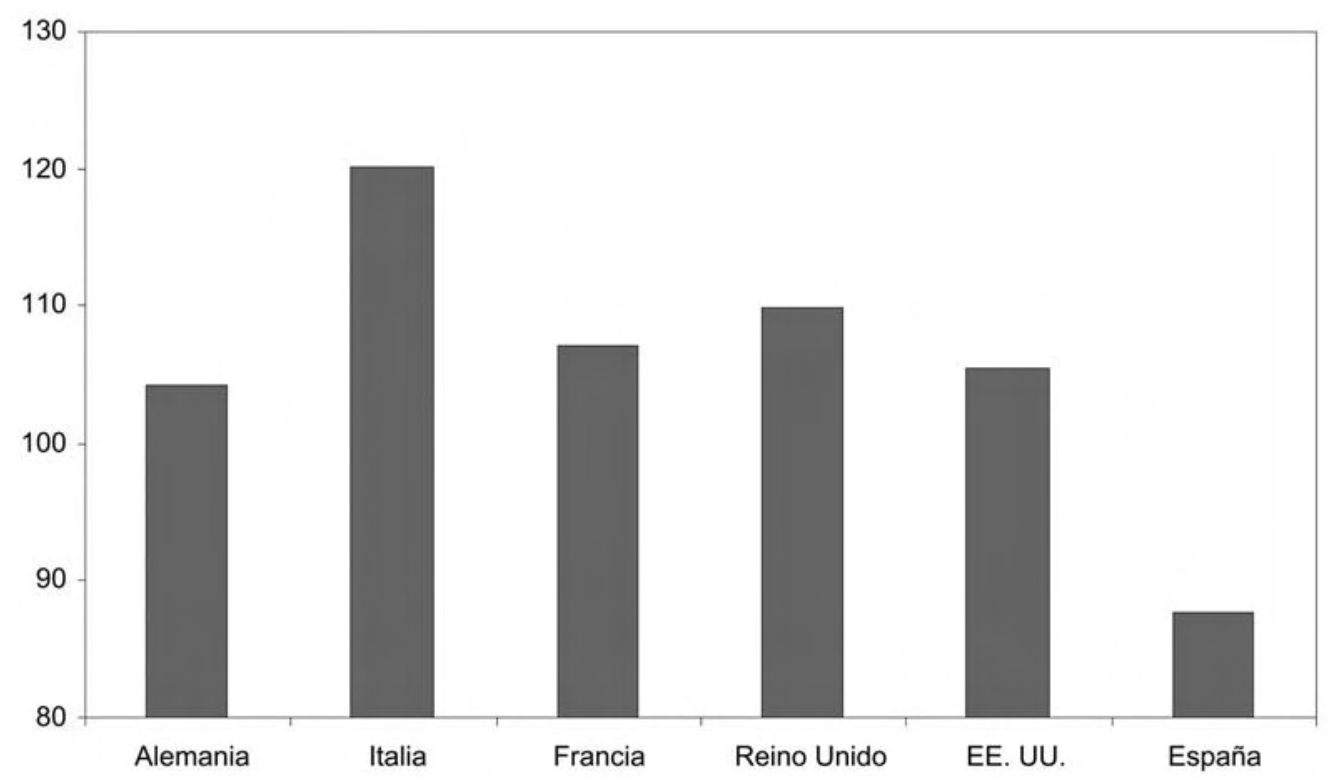

Fuentes: Calculado a partir de SEAT, Memoria y balance que el Consejo de Administración somete a la Junta general ordinaria de Accionistas correspondiente al Ejercicio 1976 en el día 28 de abril de 1977, Madrid, p. 22.

\section{Conclusiones}

Entre 1969 y 1973 las exportaciones de SEAT se multiplicaron por más de diez. En el último año, las ventas de Zona Franca al exterior no sólo eran rentables sino que, además, registraban márgenes mayores que las interiores. Durante la crisis los resultados padecieron cierta inestabilidad, pero los productos de Barcelona siguieron vendiéndose bien en el exterior. Se había empezado exportando modelos relativamente viejos (600 y 850), pero después se comercializaron productos de factura más moderna y cierta aportación ibérica en el diseño (133 y 127 4P). En 1976 SEAT exportaba un 20 por 100 de su producción y aportaba el 41 por 100 a la exportación hispana de turismos (después figuraba Citroën, con el 26 por 100). Pese a fuertes restricciones cuantitativas a la importación, España revelaba una clara ventaja comparativa en la producción de automóviles. 
El permiso de exportación, así como la autonomía de SEAT para modificar los modelos FIAT, habían sido objetivos estratégicos del INI autárquico. Estas reivindicaciones se mantuvieron durante el "desarrollismo", mientras López Bravo estuvo al frente de Industria. FIAT, tradicionalmente contraria, cambió de postura con los acuerdos de 1967 y 1970. Los hermanos Agnelli también permitieron a SEAT el uso de sus concesionarios europeos y aprobaron la creación del centro técnico de Martorell. El despegue de las exportaciones de SEAT fue favorecido por la coyuntura laboral caliente de Turín a finales de la "edad de oro". El Tratado Preferencial con la CEE de 1970 contribuyó, asimismo, al arranque exportador rebajando escalonadamente los aranceles. Por último, las desgravaciones ofrecidas desde Industria constituyeron un fuerte incentivo añadido.

Hombres como López de Letona y Pérez de Bricio trabajaron parar reabrir el sector a América, abandonando la política estratégica de apoyo a la fabricación nacional. No sólo fueron a buscar a Ford, confeccionándole un traje a medida. También llamaron a la puerta de General Motors en 1973 para que rescatase a la filial de British Leyland en España. Como SEAT había fracasado en su intento de impedir la autorización a Dearborn, su consejero delegado, Cabello de Alba, cambió de estrategia en la siguiente partida. Propuso un second-best para desactivar la amenaza de GM: SEAT se haría cargo de AUTHI a cambio, entre condiciones menores, de la prohibición definitiva de la entrada del primer fabricante mundial. Cuando fue nombrado vicepresidente económico por Arias Navarro, tuvo la ocasión de implementar su propuesta. La adquisición de 1975 no fue impuesta a SEAT, como hasta ahora ha defendido la literatura. Constituyó un pacto con el gobierno a cambio del veto "definitivo" al establecimiento de GM en España.

En 1973, SEAT había sido tentada por los incentivos de Industria y Zaragoza. Entonces todavía podía imaginarse que el ciclo expansivo de posguerra continuase, pero en 1975, cuando SEAT adquirió AUTHI, la recesión internacional arreciaba y la Zona Franca sufría un innegable exceso de capacidad. Además, SEAT había experimentado un desbordamiento de costes laborales: la partida de personal había aumentado del 15 al 27 por 100 entre 1969 y 1974. El valor de las ventas interiores había retrocedido un 15 por 100 nominal durante el último año. Sus acciones se desplomaban. Las amortizaciones experimentaban recortes brutales. En consecuencia, la compra de Landaben resultaba, cuando menos, temeraria. Si SEAT la aceptó, en lugar de rechazarla, como en 1969, fue a cambio del acuerdo duradero de exclusión del nuevo rival de Michigan.

Umberto Agnelli comunicó en directo al presidente del INI, Fernández Ordóñez, que la entrada de Ford o GM cambiaba radicalmente la política industrial de Madrid y provocaba la obsolescencia de los acuerdos de 1967 y 1970. También calificó la nueva regulación de neocolonialista. Pero acabó aceptando la compra de 
AUTHI (sin la fundición de Los Corrales de Buelna), que había combatido fieramente en 1969. No sólo pesó la prohibición definitiva de entrada de GM. La presidencia del INI ofreció a FIAT la mayoría en SEAT. Para Turín, esta novedad iba a facilitar el placet a la compra de los mejores activos de BLMC en España (Landaben y Santpedor). Los piamonteses mostraron su predisposición a tomar la mayoría, aunque solicitaron una cláusula de salvaguarda. Con las negociaciones avanzadas, hubo filtración y alarma en España. No faltaron desmentidos, pero FIAT y el INI, presidido ya por Antoñanzas, acordaron la integración de facto de la empresa hispana en la italiana, aunque no de iure.

Pese a que Madrid manifestara su disposición a hacer nuevas concesiones, el radical vuelco de la política industrial acrecentó las dudas de Turín sobre si la estrategia cooperativa adoptada hasta 1970 debía ser mantenida. La política de control de precios de los automóviles implementada en España hasta 1976 tampoco ayudó, pues chocaba con la impulsada por Italia durante el primer shock petrolero. SEAT y FIAT coincidían en que la falta de libertad para fijar los precios de sus modelos contribuía a precipitar las pérdidas en Zona Franca a comienzos de la crisis. La caída del presidente de SEAT, Sánchez Cortés, y su sustitución por el propio Antoñanzas, el 23 de febrero de 1977, conllevó el reconocimiento público de dicha crisis. Puede interpretarse como un nuevo guiño a FIAT. Pero la brutal caída de la cuota de SEAT a resultas del lanzamiento del Ford Fiesta y la creciente desconfianza de Turín en Madrid, llevarían a la casa de la Zona Franca a una situación límite en muy poco tiempo.

\section{Bibliografía}

AZNAR, Antonio, y APARICIO, María Teresa (2000): Opel España, Zaragoza, CAIA. BANCO DE BILBAO, Agencia Finaciera (varios años).

CASTRONOVO, Valerio (1999): FIAT 1889-1999. Un secolo d'istoria italiana, Milán, Rizzoli.

CATALAN, Jordi (2000): “La creación de la ventaja comparativa en la industria automovilística española, 1898-1996", Revista de Historia Industrial, 18, pp. 113-155.

-(2003): “SEAT entre l'INI i la FIAT, 1948-1980", L'Avenç. Revista d'Història i Cultura, 285, pp. 27-36.

—(2006): "La SEAT del Desarrollo, 1948-1972,", Revista de Historia Industrial, 30, pp. 143-193.

DE LA TORRE, Joseba (2002): “Antes de Volkswagen: orígenes y desarrollo de la industria del automóvil en Navarra (c. 1955-1980)", comunicación presentada al 
Seminario de la Fundación Eduardo Barreiros organizado por Jordi Nadal y José Luis García Ruiz, Universidad Complutense de Madrid.

ESTAPÉ, Salvador (2003): “Ford in Spain: the first stage (1920-1959). A multinational confronts political constraints", en BONIN, Hubert; LUNG, Yannick; y TOLLIDAY, Steven (eds.), Ford, 1903-2003: The European History, II, París, PLAGE, pp. 439-450.

GARCÍA RUIZ, José Luis (2001): “La evolución de la industria automovilística española, 1946-1999: una perspectiva comparada", Revista de Historia Industrial, 1920, pp. 133-163.

-(2003): "La industria automovilística española anterior a los "decretos Ford" (1972)" en GARCÍA RUIZ, José Luis (ed.), Sobre ruedas, Madrid, Síntesis, pp. 1393.

GARCÍA RUIZ, José Luis, y SANTOS REDONDO, Manuel (2001): ¡ Es un motor español! Historia empresarial de Barreiros, Madrid, Fundación Eduardo Barreiros-Síntesis.

GERMÁN, Luis (2003): "Made in GM. Veinte años de Opel en España", en GARCÍA RUIZ, José Luis (ed.), Sobre ruedas, Madrid, Síntesis, pp. 167-190.

GIMENO, Pablo (2002): Los SEAT 124 y 1430, Madrid, Dossat.

GIMENO, Pablo, y ROCA, Ramón (1997): Authi y los Minis españoles, Madrid, Dossat.

GONZÁLEZ DE LA FE, Pedro (2003): "SEAT en la encrucijada, (1972-2002)", en GARCÍA RUIZ, José Luis (ed.), Sobre ruedas, Madrid, Síntesis, pp. 95-126.

GONZÁLEZ LÓPEZ, Luis Ángel (2004): Los SEAT 1200/1430 Sport y 128, Madrid, Dossat.

LLORENTE GALERA, Francisco (1997): “Las estrategias de los fabricantes de automóviles. El caso SEAT, 1980-1995", en ROCA, Joan (coord.), La formació del cinturó industrial de Barcelona, Barcelona, Proa.

LUCCHETTI, Antoni (2003): "La memòria obrera de SEAT. El testimoni de dos sindicalistes", L'Avenç. Revista d'Història i Cultura, 285, pp. 57-63.

MARTÍN ACEÑA, Pablo, y COMÍN, Francisco (1991): INI 50 años de industrialización española, Madrid, Espasa Calpe.

PÉREZ SANCHÓ, Miguel (2003): "La industria del automóvil en la Comunidad Valenciana: el caso de Ford España", en GARCÍA RUIZ, José Luis (ed.), Sobre ruedas, Madrid, Síntesis, pp. 127-166.

ROCA, Ramón (2006): Nuestro Seat, Platja d'Aro, Benzina.

SOLÉ, Eulàlia (1994): SEAT (1950-1993), Barcelona, La Tempestad.

SUDRIÀ, Carles, y SAN ROMÁN, Elena (2000): “La industria del automóvil en España: una panorámica", en AA.VV., Garaje. Imágenes del automóvil en la pintura española del siglo XX, Madrid, Fundación Eduardo Barreiros. 
TOLLIDAY, Steven (2003): “The origins of Ford Europe: From multidomestic to transnational corporation, 1903-1976", en BONIN, Hubert; LUNG Yannick; y TOLLIDAY Steven (eds.), Ford, 1903-2003: The European History, vol. I, Paris, PLAGE, pp. 153-242.

TUSELL, Javier, y QUEIPO DE LLANO, Genoveva (2003): Tiempo de incertidumbre. Carlos Arias Navarro entre el franquismo y la Transición (1973-1976), Barcelona, Crítica. 